\title{
Panic Disorder and Non-Cardiac Chest Pain: A Brief Review
}

Ruth Infante, M.D.

Washington $D C$

Follow this and additional works at: https://jdc.jefferson.edu/jeffjpsychiatry

Part of the Psychiatry Commons

Let us know how access to this document benefits you

\section{Recommended Citation}

Infante, M.D., Ruth (1992) "Panic Disorder and Non-Cardiac Chest Pain: A Brief Review," Jefferson Journal of Psychiatry. Vol. 10 : Iss. 2 , Article 7.

DOI: https://doi.org/10.29046/JJP.010.2.005

Available at: https://jdc.jefferson.edu/jeffjpsychiatry/vol10/iss2/7

This Article is brought to you for free and open access by the Jefferson Digital Commons. The Jefferson Digital Commons is a service of Thomas Jefferson University's Center for Teaching and Learning (CTL). The Commons is a showcase for Jefferson books and journals, peer-reviewed scholarly publications, unique historical collections from the University archives, and teaching tools. The Jefferson Digital Commons allows researchers and interested readers anywhere in the world to learn about and keep up to date with Jefferson scholarship. This article has been accepted for inclusion in Jefferson Journal of Psychiatry by an authorized administrator of the Jefferson Digital Commons. For more information, please contact: JeffersonDigitalCommons@jefferson.edu. 


\title{
Panic Disorder and Non-Cardiac Chest Pain: A Brief Review
}

\author{
Ruth Infante, M.D.
}

\begin{abstract}
The relationship between chest pain and panic disorder is explored; after coronary artery disease and other medical diseases have been ruled out, panic disorder remains a significant contributor to morbidity. Panic disorder is treatable; hence it is important that psychiatrists educate the non-psychiatric medical community so that appropriate referrals and treatment can be made. This would lead to a decrease in health care costs.

\section{INTRODUCTION}

For many years, clinicians have faced the difficulty of managing patients who complain of chest pain, yet who have little, if any, evidence of coronary artery disease. As a result, many of these patients continue to receive cardiac medications over extended periods of time even without evidence of improvement (1). Psychiatric disorders may be overlooked as a cause of chest pain and psychiatrists doing consultation work in the medical setting need to have a high index of suspicion. There is ongoing debate on the etiology of non-cardiac chest pain (2). This paper briefly reviews the recent psychiatric developments related to the topic of non-cardiac chest pain, and includes a brief discussion of the differential diagnosis with a focus on its relationship to panic disorder.
\end{abstract}

\section{CHEST PAIN OF UNPROVEN ETIOLOGY}

Recent studies document the prevalence of chest pain in patients with little, if any, evidence of coronary artery disease on angiograms. One report on the occurrence of chest pain in a family practice setting states that $50 \%$ of patients with chest pain had unknown etiology after a 6-month period of follow-up (3). In a cardiology clinic setting, approximately $33 \%$ of patients referred for chest pain had no evidence of coronary artery disease on angiogram; another 16\% had minimal evidence of disease that was insufficient to explain the symptom of chest pain (4). A similar study showed that $37 \%$ of patients had disease insufficient to explain the complaint of chest pain with over $60 \%$ of this group having completely normal coronary angiograms (5). These figures clearly indicate that the occurrence of chest pain with insufficient clinical evidence of disease is not uncommon; this is not an insignificant problem. The cost for an organic work-up is approximately $\$ 4354$ (6). A recent North Carolina 
study estimated that each patient with non-cardiac chest pain spends about $\$ 3500$ per year to manage the pain. If these figures are applied to the estimated 90,000 patients diagnosed per year with non-cardiac chest pain, the health care costs exceed 315 million dollars (7). This is a staggering figure!

\section{DIFFERENTIAL DIAGNOSIS}

Chest pain in patients with angiographically normal coronary arteries may be of cardiac or non-cardiac origin. Among the cardiac causes are pericardial disease, valvular disease (mitral valve prolapse), hypertensive heart disease, and chest pain due to coronary artery spasm (8). In addition, Cannon and Epstien have described an entity called "microvascular angina" which they found in a sizeable percentage of patients who complained of chest pain and had no evidence of coronary artery disease on angiogram. This condition describes the presence of true myocardial ischemia caused by a disorder of the coronary microvasculature (9).

Non-cardiac causes of chest pain are principally esophageal, rheumatologic, pulmonary, and psychiatric (8). In addition to panic disorder which will be discussed further, increased neuroticism (as determined by higher scores on psychologic measures of anxiety, depression and somatization) was associated with increased somatic complaints including that of chest pain (10); it was also found that type A behavior (characterized by patterns of great drive, ambition, drive for recognition, sense of urgency and competitiveness) was a common feature among patients with non-cardiac chest pain (11).

\section{NON-GARDIAC GHEST PAIN AND PANIC DISORDER}

Studies have indicated that 34 to $40 \%$ of patients with chest pain and normal or near normal coronary arteries meet the criteria for panic disorder $(12,13,14)$. However, the chest pain associated with panic disorder is usually described as atypical or non anginal; $30-40 \%$ of patients with atypical angina met criteria for panic disorder whereas none of the patients with typical angina had panic disorder $(13,14)$. The patients who had atypical angina who met criteria for panic disorder were primarily women in their early 40's (15).

\section{MECHANISM OF CHEST PAIN IN PANIC DISORDER}

Proposed mechanisms for the development of chest pain in patients with panic disorder include hyperventilation (16) and a dysfunction in the locus ceruleus of the brain (17). Discomfort associated with breathing can arise from overuse of the thorax muscles alone; excessive use of these muscles together with localized muscular spasm induced by hyperventilation frequently causes precordial chest pain (18). Hyperventilation or overbreathing causes hypocapnia which through a series of pathophysiological mechanisms, increases neuromuscular excitability (18). Increased amounts of circulating catecholamine proposed to arise from abnormally high reactivity in the 
brain noradrenergic systems, primarily in the locus ceruleus, is related to pathologic forms of anxiety (17); its afferent and efferent neuronal pathways project to and from many areas of the brain believed to mediate behavioral responses to pain and "fear-anxiety like" animal behaviors (17).

\section{PSYCHOLOGICAL MORBIDITY}

In spite of the excellent prognosis that patients with non-cardiac chest pain have, they continue to exhibit increased morbidity with continued complaints of chest pain and with social and work dysfunction $(13,19,20)$. Follow-up studies of these patients reveal more frequent use of emergency rooms, general medical, and psychiatric care facilities and the increased use of numerous medications. These patients continue to complain of more physical restrictions associated with limited exertional capability and worsening health; they report increased incidences of depression and anxiety. Knowledge and reassurance of benign coronary arteries resulted in no improvement in psychiatric morbidity $(1,9,19,21)$.

\section{MANAGEMENT}

Modalities of treatment are available for the management of panic disorder. Pharmacologic management includes the use of high-potency benzodiazepines such as clonazepam, lorazepam, and alprazolam (22). However, a study focusing on the treatment of patients with panic disorder who have chest pain, cites the particular usefulness of alprazolam (23). The efficacy of antidepressants is also evident; however, the side effects they may provoke, such as increased heart rate and dizziness, may make the patient feel more sick $(22,24)$. In order to assure compliance it becomes necessary to inform the patient of these side effects and to start at a very low dose. Monoamine-oxidase inhibitors are also beneficial; they may have fewer side effects however, the need for avoiding specific medications as well as the need for dietary restrictions do not make this a first-line drug of choice $(22,24)$. Behavioral treatment focusing on controlled breathing and relaxation training showed a marked decrease in the frequency and the intensity of chest pain (25). Of course, the optimal treatment of panic disorder would be a combination of psychotherapy and medication (26).

\section{CONCLUSION}

Chest pain in the absence of significant coronary artery disease, when other medical diseases have been ruled out, is not an uncommon finding. Non-cardiac chest pain is strongly associated with panic disorder, and a high index of suspicion is necessary in evaluating these patients. Panic disorder is treatable and once diagnosed, appropriate management can ensue.

As psychiatrists working in the medical setting, it is important to educate our non-psychiatric colleagues in recognizing this entity so that appropriate consulta- 
tions and referrals are made. Appropriate management reduces the risk of iatrogenic complications including the use of unnecessary medications reduction in the number of visits and lengths of hospital stays and ultimately decreasing health care costs.

\section{REFERENCES}

1. Latinga LJ, Sprafkin RP, McCroskey JH, et al: One Year Psychosocial Follow-up of Patients with Chest Pain and Angiographically Normal Coronary Arteries. Ann J Cardiol 1988; 62: 209-213

2. Mayou R: Invited Review; Atypical Chest Pain. J Psychosomatic Research 1989; 33(4):393406

3. Blacklock SM: The Symptom of Chest Pain in Family Practice. J Fam Prac 1977; 4(3):429433

4. Bass C, Wade C: Chest Pain with Normal Coronary Arteries: A Comparative Study of Psychiatric and Social Morbidity. Psychological Medicine 1984; 14:51-61

5. Proudfit WL, Shirey EK, Sones FMJr: Selective Cine Coronary Arteriography; Correlation with Clinical Findings in 1,000 Patients. Circulation 1966; 23:901-910

6. Katon W: Chest Pain, Cardiac Disease and Panic Disorder. Journal of Clinical Psychiatry 1990; 51 (5, supplement):27-30

7. Richter JE, Bradley LA, Castill DO: Esophageal Chest Pain: Current Controversies in Pathogenesis, Diagnosis, and Therapy. Annals of Internal Medicine 1989; 110:66-78

8. Beitman BD, Mukerji V, Flaker G, et al: Panic Disorder, Cardiology Patients and Atypical Chest Pain. Psychiatric Clinics of North America, 1988; 2(2):387-397

9. Cannon RO, Epstein SE: "Microvascular Angina" as a Cause of Chest Pain with Angiographically Normal Coronary Arteries. American Journal of Cardiology 1988; 61:13381343

10. Costa PT Jr: Influence of the Normal Personality Dimension of Neuroticism on Chest Pain Symptoms and Coronary Artery Disease. American Journal of Cardiology 1987; 60:205265

11. Ahnve S, DeFaire V, Orth-Gomer K, et al: Type-A Behavior in Patients with Non-Coronary Chest Pain Admitted to a Coronary Care Unit. Journal of Psychosomatic Research 1979; 23:219-223

12. Beitman BD, Basha I, Flaker G, et al: Major Depression in Cardiology Chest Pain Patients without Coronary Artery Disease and with Panic Disorder. Journal of Affective Disorders 1987; 13:51-59

13. Beitman BD, Mukerji V, Lamberti J, et al: Panic Disorder in Patients with Chest Pain and Angiographically Normal Coronary Arteries. American Journal of Cardiology 1989; 63:13991403

14. Basha I, Mukerji V, Langevin P, et al: Atypical Angina in Patients with Coronary Artery Disease Suggests Panic Disorder. International Journal of Psychiatry in Medicine 1989; 19(4):341-346

15. Beitman BD, Bashi I, Flaker G, et al: Atypical or Nonanginal Chest Pain: Panic Disorder or Coronary Artery Disease. Archives of Internal Medicine 1987; 147:1548-1552

16. Bass C, Wade C, Gardner WN, et al: Unexplained Breathlessness and Psychiatric Morbidity in Patients with Normal and Abnormal Coronary Arteries. Lancet 19 March 1983

17. Charney DS, Heninger GR, Brier A: Noradrenergic Function in Panic Anxiety. Archives of General Psychiatry. Aug, 1984; 41:751-763 
18. Lum, LC: Psychogenic Breathlessness and Hyperventilation. Psychogenic Ill Health Update; 1 October, 1983:913-923

19. Papanicolaou MN, Califf RM, Hlatky MA, et al: Prognostic Implications of Angiographically Normal and Insignificantly Narrowed Coronary Arteries. American Journal of Cardiology 1986; 58:1181-1187

20. Beitman BD, Kushner MG, Basha I, et al: Follow-up Status with Angiographically Normal Coronary Arteries and Panic Disorder. JAMA March 27 1991; 265(12):1545-1549

21. Klerman GL, Weissman WM, Quellette R, et al: Panic Attacks in the Community: Social Morbidity and Health Care Utilization. JAMA Feb 13, 1991; 265(6):742-746

22. National Institutes of Health Consensus Development Conference Statement. Treatment of Panic Disorder Sept 25-27, 1991

23. Beitman BD, Basha IM, Trombka LH, et al: Alpravalam in the Treatment of Cardiology Patients with Atypical Chest Pain and Panic Disorder. Journal of Clinical Psycholpharmacology 1988; 8(2):127-130

24. Beitman BD, Basha IM, Trombka LH, et al: Pharmacotherapeutic Treatment of Panic Disorder on Patients with Chest Pain. Journal of Family Practice 1989; 28(2):177-180

25. Hegel MT, Abel GG, Etscheidt M: Behavioral Treatment of Angina-like Chest Pain in Patients with Hyperventilation Syndrome. Journal of Behavioral Therapy and Experimental Psychiatry 1989; 20(1):31-39

26. Fontaine R: Clonazepam for Panic Disorders and Agitation. Psychosomatics December 1985; 26(12,supplement):13-16 